\title{
Characterization of the Molecular Crystal L-Alaninium Oxalate by Raman Microscopy, Optical Microscopy and X-ray Powder Diffraction
}

\author{
F. J. Carrillo-Pesqueira ${ }^{1}$, R. C. Carrillo-Torres ${ }^{1}$, O. Hernández-Negrete ${ }^{1}$, M. E. Alvarez-Ramos ${ }^{1}$ and \\ J. Hernández-Paredes ${ }^{1}$ \\ 1. Posgrado en Nanotecnología, Departamento de Física, Universidad de Sonora (UNISON), Blvd. Luis \\ Encinas y Rosales S/N Col. Centro, C.P. 83000, Hermosillo, Sonora, México
}

Non-linear optical (NLO) materials have an important role in science and technology due to their applications as: frequency converters, optical data storage and processing devices, optical switches and other electro-optical devices [1].

There are studies that claim that molecular materials formed by combination of amino acids with other organic or inorganic compounds exhibit good NLO properties, low laser damage threshold and acceptable mechanical and thermal properties [2]. For example, oxalates of amino acids have displayed good NLO properties and efficient second harmonic generation (SHG). In particular, L-alaninium oxalate (LAO) is a molecular crystal with formula $\mathrm{C}_{3} \mathrm{H}_{8} \mathrm{NO}_{2}{ }^{+} \cdot \mathrm{C}_{2} \mathrm{HO}_{4}{ }^{-}$, that has attracted attention due to its good NLO performance [3]. For the present work we carried out a structural characterization of the multi-component molecular complex LAO, which has been synthetized by the slow evaporation technique and mechanochemical route.

The starting materials were purchased from Sigma and used without further recrystallization. Preparation of solutions: 1) $0.0455 \mathrm{~g}$ of L-alanine (Ala) ( $\geq 98 \%$ pure) were dissolved in $1 \mathrm{~mL}$ of deionized water; 2) $0.0450 \mathrm{~g}$ of oxalic acid (OA) (99+\% pure) were dissolved in $1 \mathrm{~mL}$ of deionized water; 3) a mixture of $0.0455 \mathrm{~g}$ of Ala and $0.0450 \mathrm{~g}$ of OA was dissolved in $1 \mathrm{~mL}$ of deionized water. The solutions were left to evaporate at room temperature. Crystals of Ala and OA were obtained after one week, whereas crystals of LAO were obtained after three weeks. For the solid-state grinding experiment a mixture of $0.2227 \mathrm{~g}$ of Ala and $0.2251 \mathrm{~g}$ of OA was grinded in a mortar until a homogeneous sample was obtained. Optical microscopy images were taken using an Olympus MIC-D digital microscope. X-ray powder diffraction (XRPD) experiments were carried out in a Panalytical XPert PRO diffractometer equipped with an $\mathrm{X}^{\prime}$ Celerator detector, using Ni-filtered $\mathrm{CuK} \alpha$ radiation. The equipment was operated at $40 \mathrm{kV}$ and $30 \mathrm{~mA}$ and the XRPD patterns were acquired from $5^{\circ}$ to $80^{\circ} 2 \theta$ with a step size of $0.017^{\circ}$. Raman spectra were measured using a HORIBA Scientific model LabRAM HR integrated with a laser source of $632 \mathrm{~nm}$.

Figure 1 shows the typical growth morphology of Ala, OA and LAO crystals. Ala and LAO show irregular forms, whereas the crystals of OA have a needle-like shape. Figure 2 shows the XRPD patterns of Ala, OA and LAO. From the data, it is clear that the reaction of Ala with OA produced a new phase, which matches the one reported by S. Natarajan et al., 2001 (LAO) [4]. Figure 3 shows the Raman spectra of Ala, OA and LAO. The characteristic bands of the $-\mathrm{NH}_{3},-\mathrm{COOH}$ and $-\mathrm{COO}^{-}$groups are observed. The $-\mathrm{NH}_{3}{ }^{+}$asymmetric stretching modes were observed at 1596 and $1592 \mathrm{~cm}^{-1}$ for Ala and LAO, respectively. Meanwhile, the $-\mathrm{NH}_{3}{ }^{+}$symmetric stretching modes were observed at 1499 and 1505 $\mathrm{cm}^{-1}$ for Ala and LAO, respectively. The spectrum of Ala suggested that the molecule is present in the form of zwitterion. The $-\mathrm{COO}^{-}$group was confirmed by the bands at 1624 and $1408 \mathrm{~cm}^{-1}$. In the spectrum of $\mathrm{OA}$ there are very strong bands around $1737 \mathrm{~cm}^{-1}$, which were assigned to vibrational 
modes of the - $\mathrm{COOH}$ groups. Further, the formation of the phase LAO was confirmed by the shifts of the $-\mathrm{COOH}$ and $-\mathrm{COO}$ bands in its Raman spectrum. In this case, the - $\mathrm{COOH}$ group produced bands at 1713, 1696 and $1460 \mathrm{~cm}^{-1}$. Meanwhile, the $-\mathrm{COO}^{-}$group was observed at 1616 and $1407 \mathrm{~cm}^{-1}$. These changes are also associated with a proton transfer from the OA to Ala.

Crystals of LAO were grown by the slow evaporation technique. Additionally, LAO phase was obtained by a mechanochemical route. The crystals of LAO showed different growth morphology in comparison with the precursors Ala and OA. XRPD experiments confirmed that LAO can be obtained in pure form by mechanochemical routes. Raman spectroscopy was a useful characterization technique to prove the proton transfer process from the OA to Ala, which leads to the formation of the phase LAO.

\section{References:}

[1] R. L. Sutherland in "Handbook of Nonlinear Optics", Marcel Dekker, Inc. (CRC Press, New York). [2] M. Fleck and A. M. Petrosyan in "Salts of Amino Acids: Crystallization, Structure and Properties", (Springer, New York).

[3] M. Vimalan, A. Ramanand and P. Sagayaraj, Crystal Research and Technology, Vol. 42 (2007), p. 1091-1096.

[4] M. S. Nandhini, R. V. Krishnakumar, S. Natarajan, Acta Cryst., Vol. E57 (2001), p. o633-o635.

[5] F. J. Carrillo-Pesqueira gratefully acknowledges the scholarship provided by CONACyT (México).
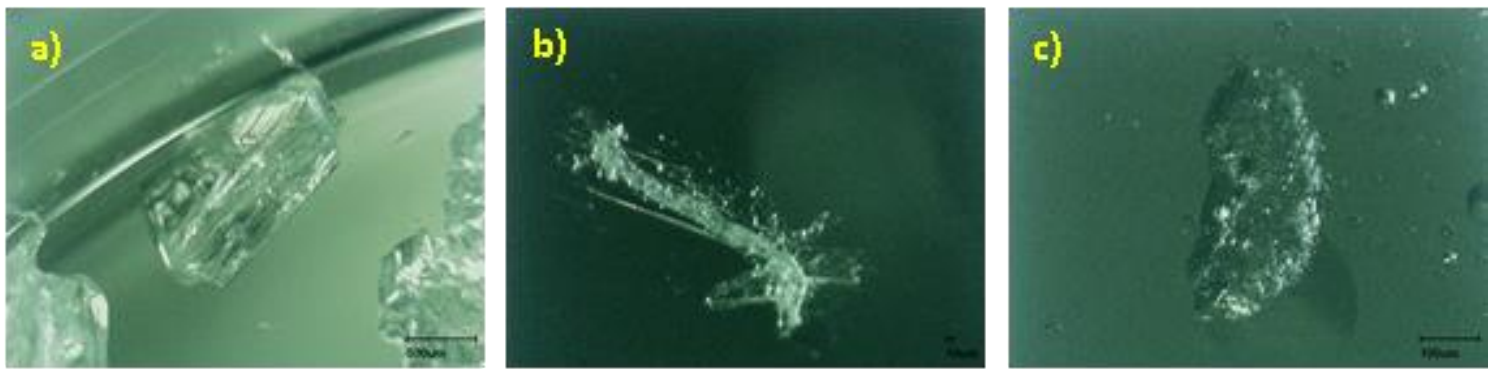

Figure 1. OM images of the growth morphology of: a) Ala, b) OA and c) LAO.

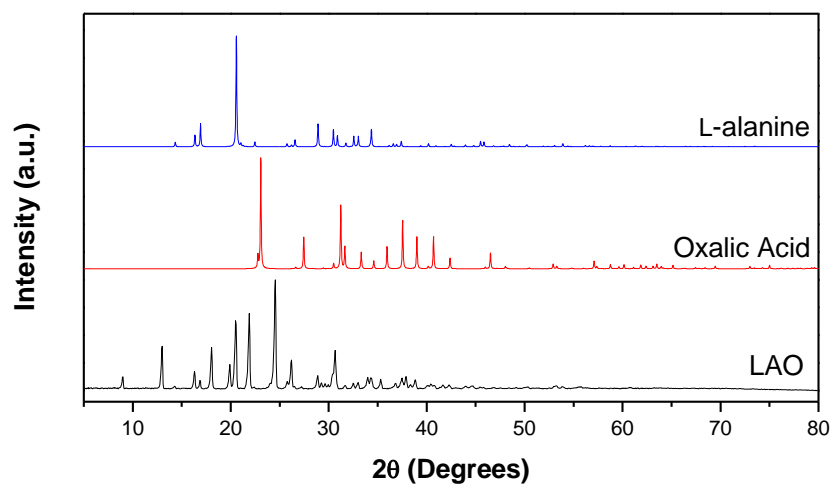

Figure 2. XRPD of Ala, OA and LAO.

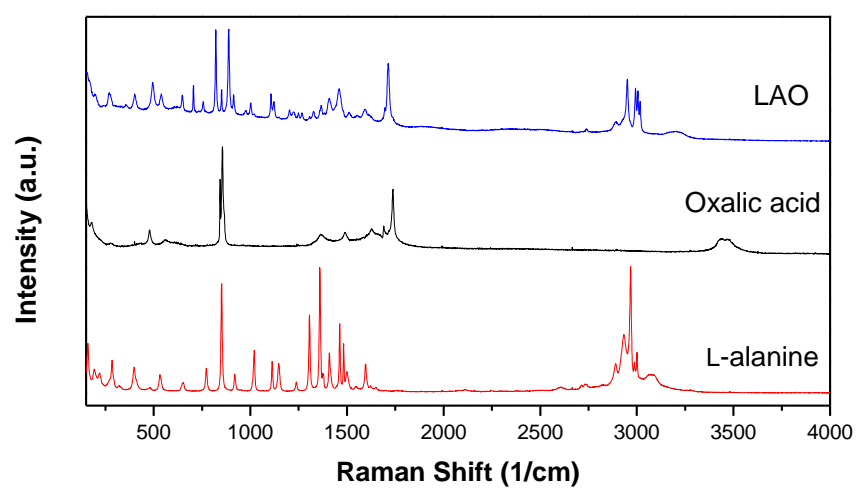

Figure 3. Raman spectra of Ala, OA and LAO. 